Western Washington University

Western CEDAR

Environmental Studies Faculty and Staff

Publications

Environmental Studies

$4-2014$

\title{
Scientists, Managers, and Assisted Colonization: Four Contrasting Perspectives Entangle Science and Policy
}

Mark W.Neff

Western Washington University, mark.neff@wwu.edu

Brendon Larson

University of Waterloo

Follow this and additional works at: https://cedar.wwu.edu/envs_facpubs

Part of the Environmental Studies Commons, and the Science and Technology Policy Commons

\section{Recommended Citation}

Neff, Mark W. \& Larson, B. M. H. (2014). Scientists, managers, and assisted colonization: Four contrasting perspectives entangle science and policy. Biological Conservation, 172, 1-7. doi:10.1016/j.biocon.2014.02.001

This Article is brought to you for free and open access by the Environmental Studies at Western CEDAR. It has been accepted for inclusion in Environmental Studies Faculty and Staff Publications by an authorized administrator of Western CEDAR. For more information, please contact westerncedar@wwu.edu. 


\title{
Scientists, managers, and assisted colonization: Four contrasting perspectives entangle science and policy
}

\author{
Mark W. Neff ${ }^{\mathrm{a}, \mathrm{b}}$ and Brendon M. H. Larson ${ }^{\mathrm{a}}$ \\ a Department of Environment and Resource Studies \\ University of Waterloo \\ 200 University Avenue West \\ Waterloo, Ontario \\ N2L 3G1 CANADA \\ blarson@uwaterloo.ca \\ ${ }^{\mathrm{b}}$ Corresponding author. Present address: \\ Environmental Science Department \\ Allegheny College \\ Box E \\ 520 N. Main St \\ Meadville, PA 16335 \\ mneff@allegheny.edu \\ Phone 8143325347 \\ Fax 8143325314
}

\section{Acknowledgements}

We thank the scientists and managers who contributed to the study and appreciate research funding from a Standard Research Grant (B. Larson) from the Social Science and Humanities Research Council of Canada (SSHRC). We are indebted to the reviewers and the editor of this journal for their insightful feedback on our work. 


\begin{abstract}
Assisted colonization is a contentious climate change adaptation strategy, but we have limited understanding of the bases of disagreement amongst scientists and far less has been done to understand the views of other stakeholders. To establish an initial empirical understanding of the terms of the debate, we conducted a $\mathrm{Q}$ method study of the views of scientists and resource managers, a key constituency because of their role in decisionmaking and implementation. We asked 24 forest managers in Ontario, Canada and 26 top-publishing ecologists and conservation biologists to evaluate their level of agreement with 33 statements about assisted colonization from the published literature and other relevant sources. The analysis revealed four main, contrasting perspectives, which we label Ecological Interventionist, Nativist Technocrat, Interventionist Technocrat, and Reluctant Interventionist; all but the Nativist Technocrats were open to assisted colonization. Disagreements between the four perspectives were defined by value-based and policy-strategic considerations at least as much as they were by varied understandings of technical issues. Assisted colonization as a climate adaptation strategy exists within the context of multiple competing and incompatible problem definitions even amongst these technical stakeholders. Based upon our findings and the relevant literature, we conclude that disputes surrounding assisted colonization will likely not be settled by additional scientific research. Rather, underlying non-technical considerations need to be brought to the fore and addressed.
\end{abstract}

Keywords: assisted colonization; climate change adaptation; Q method; science-policy interface; wicked problems 


\section{Introduction}

Species distributions and ecosystem dynamics are already showing responses to climate change (IPCC, 2007). For species to survive given projected future climate change they must either tolerate the new conditions in their current ranges, or successfully colonize and occupy new areas with appropriate conditions. Projected rates of climate change, however, will make it difficult for some species to survive or to move rapidly enough, especially given extensive habitat fragmentation and other concurrent pressures (e.g., Schloss et al., 2012; Zhu et al., 2012). Accordingly, some conservation biologists have proposed utilizing assisted colonization (also known as assisted migration and managed relocation) - the deliberate movement of species or populations outside their indigenous range with the intent of avoiding extinction (IUCN/SSC, 2013) - as a pre-emptive conservation option. Applied as a climate adaptation strategy, assisted colonization would entail moving taxa to higher latitudes or higher elevations where projected climatic conditions may enable them to survive (Hunter, 2007; McLachlan et al., 2007; Ste-Marie et al., 2011).

Assisted colonization is a contentious climate change adaptation option, and there has been a stream of opinion pieces in the scientific and management literatures arguing for and against it (e.g., Davidson and Simkanin, 2008; Hoegh-Guldberg et al., 2008; Ricciardi and Simberloff, 2009a, b). To help move these arguments forward, several recent analyses have sought to map its scientific, policy, and ethical dimensions (e.g., Camacho, 2010; Hewitt et al., 2011; Lawler and Olden, 2011; Richardson et al., 2009; Schwartz et al., 2012) and have distinguished different types of assisted colonization 
(Ste-Marie et al., 2011). However, conservation scientists' views of assisted colonization have not been empirically characterized. The extant literature presents a number of scientists' views, but there is no a priori reason to believe that they represent the breadth of opinion because we know that ecologists and conservation biologists harbor diverse views on both technical facts and conservation strategies (Moore et al., 2009; Neff, 2011; Sandbrook et al., 2011; Wallington and Moore, 2005; Young and Larson, 2011). Here, we treat scientific opinion of this conservation controversy as a subject of empirical social research in order to provide a richer understanding of the terms of the debate.

More importantly, the debate over assisted colonization has largely been framed by academic conservation scientists, so the views of other stakeholders remain underrepresented. To begin to redress this lacuna, we examine the views of the managers who would enact assisted colonization and evaluate its consequences on the ground. There is reason to suspect that managers' views will differ from those of scientists because their direct engagement with conservation practice makes them more intimately familiar with constraints to the application of ecological theory in conservation decisionmaking (Moore et al. 2009).

We characterize scientists' and managers' views alongside one another because many of the emerging questions about assisted colonization are situated at the contentious interface between science and values (Aubin et al., 2011; Camacho, 2010; Hewitt et al., 2011; Klenk and Larson, 2013; Minteer and Collins, 2010), where their views may diverge. This is especially likely given that assisted colonization is at the forefront of tensions within conservation theory and practice about the role of humans in the ongoing transformation of ecological systems (e.g., Hobbs et al., 2009; Minteer and Collins, 2010; 
Sandler, 2013). Pedlar et al (2012), for example, enumerate several differences in how foresters and conservation scientists interpret assisted migration. In short, both managers and scientists have significant roles to play in selecting, evaluating, and performing conservation activities such as assisted colonization, and thus were of interest for this study.

The main question we seek to address here is "how do scientists and managers think about assisted colonization and where do their views conflict or concur?" Our results will provide a more nuanced understanding of the dimensions of this debate as well as potential challenges to implementing assisted colonization on the ground (e.g., where the two groups have diverging views). The results of this study also provide the groundwork for subsequent social scientific research on assisted colonization and related conservation adaptation options in the face of climate change.

\section{Methods}

Rather than employing a traditional survey, a method useful for evaluating the attitudes of investigator-defined groups of people along theory-derived axes, we utilized Q method (Watts and Stenner, 2012). Q method inductively elicits individuals' understanding of a topic in a way that allows their concerns to define the axes along which they are compared. The analysis identifies shared and contested thinking about a topic along these axes, thus revealing insights typically inaccessible via survey research. Q method has frequently been used to understand the dimensions of environmental debates (e.g., Addams and Proops, 2000) and conservation policies and practices (e.g., Mattson et al., 2011, 2006; Rastogi et al., 2013). The results of a Q method study can 
provide the basis for effective design of later surveys that allow generalization from samples of participants (Danielson, 2009).

In general, we applied standard Q method practices (Figure 1), which have been thoroughly described elsewhere (Brown, 1980; McKeown and Thomas, 1988; Watts and Stenner, 2012; Webler et al., 2009). We next describe the specific steps of our study as well as an innovative analysis that we developed to identify areas of agreement and contestation in the assisted colonization debate (section 2.4).

Figure 1 approximately here

\subsection{Statement Selection}

Q method can be used to simulate a dialogue between participants and their colleagues by exposing them to statements made by people like them, and allowing them to rank those statements and justify their rankings. We first collected 781 statements comprising technical and non-technical arguments about assisted colonization and related conservation measures from a variety of sources, including articles and commentaries from the peer-reviewed literature, relevant documents from resource management entities and other stakeholders, popular media documents, and 7 phone interviews with resource managers and conservation activists (published sources in Supplementary Table 1). We looked beyond the standard scientific literature because we did not want to presume that scholarly papers would represent the breadth of considerations that might exist amongst our pool of participants.

From this broad list of statements, we used an inductive semi-structured approach to select 33 that covered the breadth of views (see Table 2; Brown, 1980). We edited 
these slightly to ensure readability and consistent syntax while maintaining original intent. Statements were then pre-tested prior to study implementation.

\subsection{Participant Selection}

The 50 participants for this study were recruited from two pools: scientists with expertise in disciplines that have engaged in the assisted colonization debate $(n=24)$, and forest managers in Ontario, Canada $(n=26)$ (demographic information in Supplementary Table 2). To provide a wide cross-section of scientific perspectives on assisted colonization, we recruited the scientists from the top publishing researchers (based on ISI Web of Science, as of July 2011) in five journals that focus on different scientific aspects of conservation: Biological Invasions, Conservation Biology, Ecology, Global Change Biology, and Restoration Ecology. We contacted 159 scientists; 24 completed the study (10 female and 14 male).

To contrast with the views of these scientists from around the world, our resource managers were foresters from Ontario, Canada. Our selection of participants from one region reflects the fact that decisions about assisted colonization will ultimately be made in local contexts. There is nonetheless significant impetus for assisted colonization in this region given additional challenges to natural movement of species northward given barriers such as the Great Lakes, extensive anthropogenic development, and fragmentation of existing habitat. Forest managers may not have views representative of other resource managers, but we focus on them here because they are considered a key player in the debate over assisted colonization (Pedlar et al., 2012). We identified forest managers in Ontario using a snowball technique (Bernard, 2006): We recruited known 
professionals in provincial ministries, asked them to participate, and then asked them to name other contacts with relevant positions. We continued the process until we received no further names, suggesting that we had contacted the core of the management community. We contacted a total of 54 foresters and forest managers; 26 completed our study (4 female and 22 male).

These sample sizes are typical for Q method studies, but the low participation rate raises some questions as to whether the views captured in this study are representative of those existing in the broader scientific and management populations. We are careful throughout our analysis to note that our conclusions do not depend on representing the full range of possible attitudes, but rather stem from the fact that multiple competing perspectives exist amongst our participants.

\subsection{Data Collection}

We utilized a software program, FlashQ (http://qmethod.org/forms/flashq.zip), to allow participants to access and conduct the $\mathrm{Q}$ sorting exercise regardless of their location. We provided instructions to guide them through the process of sorting the statements into a Gaussian distribution (Table 1), from those with which they most disagreed to those with which they most agreed, using the following conditions of instruction. We introduced the sorting exercise with the following statement of our purpose:

This study is to elicit your understandings and opinions about humans actively moving species to new areas as a climate change adaptation strategy. These activities are sometimes known as assisted colonization, assisted migration, or several other names. For this survey, we will refer to the act of moving species from place to place as a climate change adaptation strategy as " $A C$. " 
We then asked participants to read each statement and place it in one of three piles depending on whether they agreed, disagreed, or felt unsure/neutral about it. Participants then read through their "agree" pile to identify the two statements with which they most strongly agreed, did the same to identify those from the "disagree" pile with which they most strongly disagreed, and placed those statements at the extremes of the distribution. Participants then alternated placing statements from the "agree" and "disagree" piles until they had filled the Gaussian distribution, using the "unsure/neutral" pile when necessary. Participants were reminded that they could refine their ranking of any statement at any point. Upon completing the sorting exercise, each participant was asked to explain her or his reaction to the two statements that s/he most strongly agreed with and disagreed with. Each then provided basic demographic information in a brief survey to verify job description, training, and other characteristics.

\section{-Table 1 approximately here}

\subsection{Data Analysis}

We used the PQMethod software program (vers. 2.11; http://qmethod.org/links) to perform principal components analysis on the results, using persons as variables, to identify participants' shared understandings of the topic (called 'factors' in the Q method literature). We pooled the scientist and manager participants into a single analysis because they would sort into different factors if there were any systematic differences in their thinking (see Donaldson, 2010).

There is no single objective criterion for how many factors should be extracted in a Q method analysis (Watts and Stenner, 2012). We considered extracting between one and eight factors. A three-factor solution minimized the correlation between factors, but 
we settled on a four-factor solution that explained $54 \%$ of the total variance because - as explained in greater detail in the results - the fourth factor helped to identify key tensions amongst participants generally open to considering assisted colonization as a management strategy. We opted for varimax rotation because the purpose of the study was to identify the dominant mental frameworks within our participant community and thus we wanted the data to drive the analysis (Watts and Stenner, 2012). Forty-one of the 50 participants loaded significantly on one of the four factors at the $\alpha=0.05$ level and were thus considered to be defining variables for those factors (Supplementary Table 2). PQmethod then constructs a factor array, which is a table of weighted average scores ( $\mathrm{z}$ scores) of the defining variables' rankings of each statement (Table 2; Schmolck, 2002).

To identify areas of agreement and disagreement within the assisted colonization debate, we calculated standard deviations for each statement across the four factors. High standard deviation indicates divergent rankings of that statement.

In $\mathrm{Q}$ method, the statements receiving large positive or negative ratings are those that participants feel most strongly about and they weigh most heavily in the statistical identification of the factors (Watts and Stenner, 2012). To identify the statements that received the strongest average responses, positive or negative, across the four factors, we calculated the mean of the absolute values of the four factors' reconstructed $\mathrm{z}$ scores for each statement, a statistic we term "salience." The generalized calculation is as follows:

Salience $_{s_{x}}=\frac{\left|z_{1}\right|+\left|z_{2}\right|+\ldots\left|z_{n}\right|}{n}$, where $s_{x}$ is the statement number, $z_{n}$ is each factor's z score for that statement, and $n$ is the number of factors ( $n=4$ in our case). We suggest that those statements with the highest resulting values are the most salient to the respondents' ways of thinking about assisted colonization. This is, to the best of our knowledge, a 
novel way of treating Q method data, but one that is useful for analysts seeking to distill the essence of controversies to understand core areas of dissent and agreement. Statements with high salience and high standard deviations are those that represent tightly held and controversial views.

In the final stage of the analysis, we used all available sources of data - including the quantitative results of the $\mathrm{Q}$ analysis and qualitative interview data - to write narratives that characterized the shared thinking associated with each factor. We did so using grounded theory; that is, by building, revisiting, and revising preliminary narratives until they were consistent with all the data (Glaser and Strauss, 1967); both authors participated in this process. We identified the statements that were most relevant to each factor (those that received the highest and lowest $\mathrm{z}$ scores in the factor array) and examined the explanations that participants associated with relevant factors offered for

those statements (Eden et al., 2005; Watts and Stenner, 2012; Webler et al., 2003, 2009). The narratives that emerged from this analysis represent our interpretation of the shared values espoused by participants associated with each factor. Each factor was given a title broadly indicative of that factor's approach to assisted colonization (Table 3).

\section{Results}

\subsection{Factor Descriptions}

Four factors emerged from our analysis (Tables 2, 3). In the following sections, we briefly describe the logic associated with each factor. 


\section{Factor 1: Ecological Interventionists}

The Ecological Interventionists accepted significant human management of "nature," believing conventional conservation strategies to be necessary for the conservation of biodiversity (Statement 9), but not sufficient in an era of climate change, thus necessitating options such as assisted colonization (Statement 14). The narratives of both resource managers and scientists associated with this factor provide a similar underlying logic, exemplified by the scientist who wrote that assisted colonization "is demonstrably the most effective method of preserving biodiversity. Of course, it's not without difficulties and probably cannot succeed if it's the only method used. This is why I think assisted colonization in some cases will be required for species protection." A manager similarly suggested that assisted colonization will not work without complementary conservation measures: "Strategic assisted colonization is totally dependent on maintaining as much natural in situ functioning biodiversity as possible. Zoos and seed banks are important additional tools for conservation but by no means good substitutes for in-situ functioning ecosystems."

The Ecological Interventionists strongly rejected the suggestion that traditional conservation of native populations makes little sense given changed ecosystem conditions (Statement 20). Several described this statement as "defeatist," and another rejected it as follows: "Preserving native populations is ALWAYS the best policy - it's the height of arrogance to assume that we can replicate the complex web of interactions that has evolved in a native system in a managed one." 
These respondents did not perceive assisted colonization to be a radical transformation of natural ecosystems, but rather a necessary response to anthropogenic climate change and an extension of natural processes: "Species have been moving around throughout geological time, mostly under the influence of climate change. It is a very anthropocentric and short term view to believe that all species should remain exactly where they were perceived to be over the past few hundred years." Change is an essential characteristic of ecosystems: "This is simply a statement of fact, supported by millennia of climate-related species movements."

We do not, according to this logic, have the luxury of conducting "a vast research program before assisted colonization can begin" (Statement 7). "There is no time!" one participant responded. Others emphasized that assisted colonization is already occurring. Another suggested that while "more research is always needed, [awaiting a vast research program] creates a situation where we do nothing but throw a bit of money towards monitoring as species and communities slide into functional extinction."

The Ecological Interventionists were less concerned than their peers by the idea that citizen groups with appropriate expertise might participate in assisted colonization (Statement 1), but still believed in the importance of following approved and reviewed plans (Statement 11). One participant reported "I view humans as part of nature, and therefore human interests as part and parcel of our interests in sustaining ecosystem productivity and stability." Further indicating some tension about the role of science in assisted colonization decision making, a manager wrote that we need structured decisionmaking methods because scientists tend to resort to a biased "natural is best" ideology. 


\section{Factor 2: Nativist Technocrats}

The Nativist Technocrats are committed to saving species from potential extinction, but prefer to do so by minimizing human influence on nature rather than by intervening in ecosystems. The "Technocrat" portion of the title for this group reflects their strong rejection of movement of species by expert citizens (Statement 1); they believe that scientists should retain decision-making authority and professionals should conduct conservation work.

The Nativist Technocrats agreed that traditional conservation of habitats and species is important (statement 9), but whereas the other groups felt that assisted colonization had a role to play, the Nativist Technocrats rejected it (Statements 6, 14), not least because of concerns about introducing diseases or invasive species (Statements 3, 15). They considered assisted colonization to be a form of risky ecological roulette (Statement 13). One scientist responded in all-capital letters that there is "NO SCIENTIFIC EVIDENCE" that it might help to mitigate biodiversity loss. Another scientist asked, "Do we keep moving species further and further poleward or uphill as the climate warms? Until we run out of hill or latitude? If global warming is not mitigated it will be catastrophic for ecosystems and humanity. Assisted colonization is a hopeless strategy for dealing with climate change and may provide the illusion that mitigation is not necessary."

The Nativist Technocrats also rejected the proposal to design conservation strategies around species' functional roles (Statement 23). Both managers and scientists within the group offered examples of well-intentioned species introductions that went 
awry, and several scientists justified their rejection of that statement by saying that it is anthropocentric.

\section{Factor 3: Interventionist Technocrats}

In contrast to the Nativist Technocrats, the Interventionist Technocrats were amenable to assisted colonization as an important and necessary conservation tool (e.g., Statement 2). They were technocratic insofar as they strongly disagreed with basing ecological practice on people's preferences (Statement 10). One clarified that these decisions "should be based on science" and another that "bias play[s] too important [a] part of human make up" to rely on people's preferences. They were the only group to disagree that we require "a framework for debates about subjective values surrounding species conservation" (Statement 16) and strongly felt that citizen groups with appropriate expertise should not be allowed to move species (Statement 1). This factor placed more faith in objective science providing solutions than did the other factors, despite the fact that it comprised only forest management participants. We further discuss the composition of this factor in the Discussion, below.

These respondents felt that the technique posed significant risks that must be weighed carefully (Statement 8); one listed a handful of pests inadvertently transported with species in the past in his articulation of the risks. However, they also held the perspective, unique amongst the sampling pool, that endangered species laws are overly restrictive and thus need to be changed to successfully manage ecosystems in the face of climate change (Statement 5). One justified this by writing that these laws constitute 
"rigid standards imposed on dynamic systems," which leads them to "conflict with economic, social, and environmental priorities."

\section{Factor 4: Reluctant Interventionists}

The Reluctant Interventionists were similar to the Ecological Interventionists (a correlation of 0.613 ), but we retained it as a distinct factor because of its unique perspectives on two issues. First, as the name indicates, the Reluctant Interventionists were far more cautious about implementing assisted colonization. Compared to Ecological Interventionists, they were more concerned about potential negative implications of introduced species (Statements 17, 15,4) and less pessimistic about the possibility of maintaining viable populations of native species under future climatic conditions (Statement 20). They did not easily embrace the idea of moving species, and none were optimistic that it will prove to be a panacea. Second, in contrast to the Ecological Interventionists who were neutral on the idea, this group emphatically rejected the statement that well-intentioned and informed citizen groups should be able to undertake assisted colonization activities without government approval (Statement 1) and expressed comparative openness to ethical rejections of assisted colonization.

Despite their rejection of non-expert implementation of assisted colonization, they agreed that we need "a framework for debates about [related] subjective values (Statement 16)." One manager cited significant challenges in figuring out how to "balance the interests of different interest groups with that of the public and with future generations." In general, this group felt more strongly than the other groups that public values must be considered in assisted colonization decision-making (e.g., Statements 10, 
$16,23)$. Retaining this group in our analysis allows us to highlight their systematically differing opinions on these topics.

Of the four perspectives, the Reluctant Interventionists most strongly believed that ecosystems will change and species will go extinct regardless of whether we enact assisted colonization (Statement 4). They felt that humans affect all ecosystems, and that further change would be inevitable even without human influence of any kind. They concluded that the risks of acting should be weighed against those of not acting (Statement 8), with one scientist elaborating that "I don't think there are perfect solutions nor perfect answers, so this approach [weighing risks] represents the best way forward."

Despite the significant risks they identify (e.g., Statements $3,15,17$ ), these respondents did not conclude that we need more research before utilizing assisted colonization (e.g., Statement 7), a sentiment shared with the Ecological Interventionists. They noted both that land managers are already doing things that could be considered assisted colonization and that waiting for definitive results would be detrimental.

\subsection{Critical Areas of Agreement and Contestation}

Highly salient statements with low standard deviations indicate that some of the risks of assisted colonization are widely accepted (Table 2). For example, there was relative agreement that assisted colonization carries disease and genetic risks to recipient ecosystems (Statement 3) and that ecosystems will change regardless of management activities (Statement 4).

Amongst tightly-held and contested ideas (bold statements), the single most salient statement (\#1) deals with who should be allowed to conduct assisted colonization activities, and the most contested one concerns the role of endangered species laws in 
species conservation (Statement 5). Some of the contestation over the latter statement may be due to the fact that managers in our study were likely thinking of their Canadian legal system, whereas scientific participants likely had any number of other contexts in mind. Other statements with high salience and standard deviations relate to the appropriateness of using people's preferences as a basis for ecological practice and policy (Statement 10) and the need for a framework for debates about subjective values relating to assisted colonization (Statement 16), which suggests contestation about whether values should play a role in decision making and/or whether they should be openly debated. These highly salient and contested statements are non-technical in nature.

\section{Discussion}

Q method studies can be designed to identify, and develop nuanced understanding of, shared perspectives or views on controversial subjects. In contrast to typical surveys, the results are not intended to be quantitatively generalizable because the method utilizes small and non-random participant samples. This study does not, for example, lend information about how common the thinking behind these factors is in the relevant communities, nor does it allow us to evaluate whether scientists and managers have distinct modes of thinking on average. In our results, both scientists and managers were represented as defining variables for all of the factors except Factor 3, the Interventionist

Technocrats, which comprised managers exclusively (Supplementary Table 2). However, it is not possible to conclude that Factor 3 represents attitudes that are exclusive to managers generally, or Canadian managers specifically. Furthermore, our forest 
management participant pool represents a limited geography and focal ecosystem type, so the results should not be taken as representative of managers in other contexts.

The results indicate that there are multiple well-developed ways of thinking about assisted colonization, and each highlights contrasting concerns. Many of the areas of contestation that we identified have not played prominent roles in the scientific literature, in part because they involve policy strategic considerations, ideas about the appropriate role of values in ecological management, and normative ideas about who should be making decisions, rather than technical issues normally debated in the literature. In particular, concerns about the interface between assisted colonization policy and contemporary endangered species laws have only been briefly considered (e.g., Shirey and Lamberti, 2010), yet were highly salient overall in our analysis.

Our results suggest that in the perspective of these scientists and managers, assisted colonization entails a tangle of technical, policy strategy, and value-based considerations. It invokes concerns related to invasion potential, population genetics, and the ecological impacts of management activities; it speaks to some participants' ethical concerns about human responsibility to natural systems; and it is entangled in other participants' broader policy goals, such as maintaining and strengthening conservation laws and fostering a broader cultural conservation ethic. Our respondents considered values and public policy preferences to be central in defining their responses to assisted colonization. Assisted colonization is, to use Weinberg's (1972) phrase, trans-scientific; that is, it is discussed in the language of science and its desirability is at least partially contingent upon scientific findings, but the issue is so deeply entwined with value and policy considerations that proposals cannot be evaluated exclusively based upon 
scientific considerations. Further biological study, therefore, is not likely to settle the non-technical disagreements that underlie the disputes seen already in the technical literature.

Ecological management in the face of climate change is a multifaceted and multilayered policy problem. Accordingly, there is conflict not only concerning the likely outcome of assisted colonization (Statement 13), but also over human ethical obligations toward nature, and appropriate actions to pursue under conditions of uncertainty. Other considerations that our participants highlighted are more about process, decision-making authority, and, indeed, balancing management interventions with the possible legal and cultural changes that may be necessary - such as altering endangered species laws - for such activities to take place. For some participants, assisted colonization is foolhardy because it could weaken both formal endangered species laws and cultural norms that protect species in their native habitats; for others, assisted colonization is a necessary but unappealing strategy to conserve species otherwise doomed to extinction by human actions. Further complicating discussions of ecosystem management options, the activities that different stakeholders may label as assisted colonization can differ dramatically (see IUCN/SSC, 2013; Seddon, 2010; Ste-Marie et al., 2011).

Rittel and Webber (1973) coined the term "wicked problem" to describe dilemmas such as those surrounding assisted colonization. Wicked problems are nested and stakeholders have mutually exclusive definitions of the problem: Releasing a species to an area outside its indigenous range, a potential solution to one problem, is in itself a problem that other conservation scientists and managers seek to avoid. The lack of a consistent problem definition - which derives as much from the variability of 
ecosystems, potential assisted colonization activities, and ideas of ethical obligations toward nature as it does from contested technical considerations - precludes development of a scientific consensus about the desirability of assisted colonization unless technical components are isolated from value-based considerations. There is no objective test that would settle relevant debates once and for all, and every potential species introduction could have different implications. Furthermore, those implications may play out over the course of centuries, and it would be impossible to incontrovertibly disentangle the effects of one management action from the many other natural and anthropogenic impacts on and dynamics within recipient and donor populations and ecosystems. The implications, of both acting and not acting, are potentially significant ecologically, economically, and culturally. Any choice to act or not to act is thus potentially endlessly contestable if it is imposed by technical communities and thus perceived by the public to lack democratic legitimacy (see Sarewitz, 2004). These characteristics are typical of wicked problems, and they suggest additional technical information will likely neither dispel the controversies within the scientific and management communities nor prevent them from emerging amongst broader constituencies.

Two conditions could ensure that assisted colonization does not become mired in public contestation: The public could remain unengaged in the controversy, or relevant publics could be enrolled in a discussion of the values underlying conservation such that they feel ownership of whatever decisions are made. Although countless ecosystem management decisions made without consulting the public fail to invoke strong public opposition, we expect that would be an unlikely outcome with assisted colonization given the fact that citizen groups are already actively moving species outside their historic 
ranges as a climate adaptation strategy (e.g., "Torreya Guardians," n.d.). Dissatisfied citizens frequently derail resource management decisions in which they feel that they have not been involved (Chase et al., 2004; Wondolleck and Yaffee, 2000).

Conservationists may have no option but to openly engage the public regarding the non-technical controversies underlying the debate over assisted colonization. These discussions would necessarily occur in local contexts, allowing sensitivity to differing ecological contexts, legal structures, and cultural norms. Each contextualized decisionmaking process must take advantage of the relevant scientific knowledge, while acknowledging both the values underlying the dispute and the inevitable uncertainties associated with managing dynamic ecosystems for projected future conditions. That humility might allow conservation research and practice to inform and be informed by a broader societal discussion, thereby taking full advantage of science's strengths in generating technical information and democracy's systems to adjudicate value disputes (Funtowicz and Ravetz, 1993; Sarewitz, 2004).

\section{References}

Addams, H., Proops, J.L.R., 2000. Social discourse and environmental policy: an application of Q methodology. Edward Elgar Pub, Northampton, MA.

Aubin, I., Garbe, C.M., Colombo, S., Drever, C.R., McKenney, D.W., Messier, C., Pedlar, J., Saner, M.A., Venier, L., Wellstead, A.M., 2011. Why we disagree about assisted migration: Ethical implications of a key debate regarding the future of Canada's forests. The Forestry Chronicle 87, 755-765.

Bernard, H.R., 2006. Research methods in anthropology: qualitative and quantitative approaches. Rowman Altamira, Lanham, MD.

Brown, S.R., 1980. Political Subjectivity: Applications of Q Methodology in Political Science. Yale University Press, New Haven, CT.

Camacho, A.E., 2010. Assisted Migration: Redefining Nature and Natural Resource Law Under Climate Change. Yale Journal on Regulation 27, 171-397. 
Chase, L.C., Decker, D.J., Lauber, T.B., 2004. Public Participation in Wildlife Management: What Do Stakeholders Want? Society \& Natural Resources 17, 629-639.

Danielson, S., 2009. Q Method and Surveys: Three Ways to Combine Q and R. Field Methods 21, 219-237.

Davidson, I., Simkanin, C., 2008. Skeptical of assisted colonization. Science 322, 1048b.

Donaldson, C., 2010. European Value of a Quality Adjusted Life Year ( No. SP5ACT-2007-044172). Newcastle University.

Eden, S., Donaldson, A., Walker, G., 2005. Structuring subjectivities? Using Q methodology in human geography. Area 37, 413-422.

Funtowicz, S.O., Ravetz, J.R., 1993. Science for the post-normal age. Futures 25, 739755.

Glaser, B.G., Strauss, A.L., 1967. The discovery of grounded theory: strategies for qualitative research. Aldine de Gruyter, New York.

Hewitt, N., Klenk, N., Smith, A.L., Bazely, D.R., Yan, N., Wood, S., MacLellan, J.I., Lipsig-Mumme, C., Henriques, I., 2011. Taking stock of the assisted migration debate. Biological Conservation 144, 2560-2572.

Hobbs, R.J., Higgs, E., Harris, J.A., 2009. Novel ecosystems: implications for conservation and restoration. Trends in Ecology and Evolution 24, 599-605.

Hoegh-Guldberg, O., Hughes, L., McIntyre, S., Lindenmayer, D.B., Parmesan, C., Possingham, H.P., Thomas, C.D., 2008. Ecology. Assisted colonization and rapid climate change. Science 321, 345.

Hunter, M.L., 2007. Climate change and moving species: furthering the debate on assisted colonization. Conservation Biology 21, 1356-1358.

Intergovernmental Panel on Climate Change, 2007. Climate change 2007: impacts, adaptation and vulnerability: contribution of Working Group II to the fourth assessment report of the Intergovernmental Panel on Climate Change. Cambridge University Press, Cambridge, U.K.; New York.

IUCN/SSC, 2013. Guidelines for Reintroductions and Other Conservation Translocations. IUCN Species Survival Commission, Gland, Switzerland.

Klenk, N.L., Larson, B.M.H., 2013. A rhetorical analysis of the scientific debate over assisted colonization. Environmental Science \& Policy 33, 9-18.

Lawler, J.J., Olden, J.D., 2011. Reframing the debate over assisted colonization. Frontiers in Ecology and the Environment 9, 569-574.

Mattson, D., Clark, S.G., Byrd, K.L., Brown, S.R., Robinson, B., 2011. Leaders' perspectives in the Yellowstone to Yukon Conservation Initiative. Policy Sci 44, 103-133.

Mattson, D.J., Byrd, K.L., Rutherford, M.B., Brown, S.R., Clark, T.W., 2006. Finding common ground in large carnivore conservation: mapping contending perspectives. Environmental Science \& Policy 9, 392-405.

McKeown, B., Thomas, D., 1988. Q Methodology, Quantitative applicatins in the social sciences. Sage Publications Inc, Newbury Park.

McLachlan, J.S., Hellmann, J.J., Schwartz, M.W., 2007. A framework for debate of assisted migration in an era of climate change. Conservation Biology 21, 297302. 
Minteer, B.A., Collins, J.P., 2010. Move it or lose it? The ecological ethics of relocating species under climate change. Ecological Applications 20, 1801-1804.

Moore, S.A., Wallington, T.J., Hobbs, R.J., Ehrlich, P.R., Holling, C.S., Levin, S., Lindenmayer, D., Pahl-Wostl, C., Possingham, H., Turner, M.G., Westoby, M., 2009. Diversity in Current Ecological Thinking: Implications for Environmental Management. Environmental Management 43, 17-27.

Neff, M.W., 2011. What research should be done and why? Four competing visions among ecologists. Frontiers in Ecology and the Environment 9, 462-469.

Pedlar, J.H., McKenney, D.W., Aubin, I., Beardmore, T., Beaulieu, J., Iverson, L., O’Neill, G.A., Winder, R.S., Ste-Marie, C., 2012. Placing Forestry in the Assisted Migration Debate. BioScience 62, 835-842.

Rastogi, A., Hickey, G.M., Badola, R., Hussain, S.A., 2013. Diverging viewpoints on tiger conservation: A Q-method study and survey of conservation professionals in India. Biological Conservation 161, 182-192.

Ricciardi, A., Simberloff, D., 2009a. Assisted colonization: good intentions and dubious risk assessment. Trends in Ecology and Evolution 24, 476-477.

Ricciardi, A., Simberloff, D., 2009b. Assisted colonization is not a viable conservation strategy. Trends in Ecology and Evolution 24, 248-253.

Richardson, D.M., Hellmann, J.J., McLachlan, J.S., Sax, D.F., Schwartz, M.W., Gonzalez, P., Brennan, E.J., Camacho, A., Root, T.L., Sala, O.E., Schneider, S.H., Ashe, D.M., Clark, J.R., Early, R., Etterson, J.R., Fielder, E.D., Gill, J.L., Minteer, B.A., Polasky, S., Safford, H.D., Thompson, A.R., Vellend, M., 2009. Multidimensional evaluation of managed relocation. Proceedings of the National Academy of Sciences 106, $9721-9724$.

Rittel, H.W.J., Webber, M.M., 1973. Dilemmas in a general theory of planning. Policy Sciences 4, 155-169.

Sandbrook, C., Scales, I.R., Vira, B., Adams, W.M., 2011. Value Plurality among Conservation Professionals. Conservation Biology 25, 285-294.

Sarewitz, D., 2004. How science makes environmental controversies worse. Environmental Science and Policy 7, 385-403.

Schmolck, P., 2002. PQManual [WWW Document]. PQManual. URL http://www.lrz.de/ schmolck/qmethod/pqmanual.htm (accessed 7.29.10).

Schwartz, M.W., Hellmann, J.J., Mclachlan, J.M., Sax, D.F., Borevitz, J.O., Brennan, J., Camacho, A.E., Ceballos, G., Clark, J.R., Doremus, H., 2012. Managed relocation: integrating the scientific, regulatory, and ethical challenges. BioScience 62, 732-743.

Seddon, P.J., 2010. From Reintroduction to Assisted Colonization: Moving along the Conservation Translocation Spectrum. Restoration Ecology 796-802.

Shirey, P.D., Lamberti, G.A., 2010. Assisted colonization under the US Endangered Species Act. Conservation Letters 3, 45-52.

Ste-Marie, C., A. Nelson, E., Dabros, A., Bonneau, M.-E., 2011. Assisted migration: Introduction to a multifaceted concept. The Forestry Chronicle 87, 724-730.

Torreya Guardians [WWW Document], n.d. URL http://www.torreyaguardians.org/ (accessed 8.9.10).

Wallington, T.J., Moore, S.A., 2005. Ecology, Values, and Objectivity: Advancing the Debate. BioScience 55, 873. 
Watts, S., Stenner, P., 2012. Doing Q Methodological Research: Theory, Method \& Interpretation. SAGE Publications Ltd.

Webler, T., Danielson, S., Tuler, S., 2009. Using Q method to reveal social perspectives in environmental research. Social and Environmental Research Institute, Greenfield, MA.

Webler, T., Tuler, S., Shokey, I., Stern, P., Beattie, R., 2003. Participation by Local Governmental Officials in Watershed Management Planning. Society \& Natural Resources 16, 105-121.

Weinberg, A.M., 1972. Science and trans-science. Minerva 10, 209-222.

Wondolleck, J.M., Yaffee, S.L., 2000. Why Collaboration?, in: Making Collaboration Work: Lessons from Innovation in Natural Resource Management. Island Press, pp. 23-45.

Young, A.M., Larson, B.M.H., 2011. Clarifying debates in invasion biology: A survey of invasion biologists. Environmental Research 111, 893-898.

\section{Figure and Table Legends}

Figure 1: Flow chart of methods. Q method comprises four major steps: statement selection (blue), administering the survey to participants (yellow), statistical analyses to identify groups with similar statement rankings and characterize those groups (red), and qualitative analysis of the findings (orange)

Table 1: Forced choice Gaussian distribution.

Table 2: The 33 statements to which participants responded, sorted by "salience". For each statement, we provide $\mathrm{z}$ scores for each of the four factor groups, with associated color-coding: stronger hues of green indicate greater agreement and stronger hues of red indicate greater disagreement. High salience indicates that a statement was a central 
consideration for the four factors (high positive or negative scores, on average), and a high standard deviation indicates greater disagreement between the four factors. Statements with both salience and standard deviation above average are indicated in bold.

Table 3 The four factors and the correlations between them. "AC" stands for assisted colonization.

Supplementary Table 1: Published sources of statements forming the concourse.

Supplementary Table 2: Participant characteristics and factor loadings. We list each scientist's self-described expertise (with focal species in brackets) and focal geographical region, with their gender, highest degree, and current location in a superscript. We list each forest manager's self-described job, with their gender and highest degree in a superscript; all forest managers were located in Ontario, CA. Defining variables (shaded grey) are significant at the $\mathrm{p}<0.05$ level (for further explanation, see Brown, 1980, pp. 222-223). 


\begin{tabular}{|l|l|l|l|l|l|l|l|l|l|}
\hline Ranking value & -4 & -3 & -2 & -1 & 0 & 1 & 2 & 3 & 4 \\
\hline Number of items & 2 & 3 & 4 & 5 & 5 & 5 & 4 & 3 & 2 \\
\hline
\end{tabular}


2 There is little ecological value to be gained from AC.

3 Introduced organisms can carry diseases and parasites or can alter the genetic structure of local populations.

4 Whether managers engage in AC or not, ecosystems will still be invaded and change, and some species will likely go extinct.

5 Endangered species laws create excessive burdens on organizations attempting to save species and thus should be altered.

6 Species should not be moved outside their native range.

7 We need to complete a vast research program before $A C$ can begin.

8 The risk of damage from acting should be weighed against the risk of not acting.

9 Successful conservation efforts must focus on preserving habitats and diverse communities of organisms.

10 People's preferences regarding species are an inappropriate basis for ecological practice and policy.

Species recovery needs to be done by people who know what they're doing, under approved and reviewed scientific plans.

2 Allowing species to respond naturally is always the first and best option.

$13 \mathrm{AC}$ is ecological roulette, likely to cause more problems than it solves.

14 Moving species outside their historic ranges may mitigate biodiversity loss due to climate change.

15 Even species that are threatened in their native ranges could become invasive in a new evolutionary context.

16 We need a framework for debates about subjective values surrounding species conservation.

17 Relocated plant species are unlikely to cause extinctions.

18 Categorical ethical claims against the use of AC are unfounded.

19 AC elevates the importance of endangered species over native ecosystems.

20 Maintaining viable levels of native populations makes little sense as ecosystems become inhospitable to native biota and more amenable to non-natives.

21 There is a societal responsibility to take steps to protect species threatened with extinction.

$22 \mathrm{AC}$ will show just how much less costly and problematic it would be to engage in policies to mitigate climate change.

23 We should be talking about establishing species that perform the ecological and social roles that we want.

24 The strategy of waiting to see what happens neglects our values and responsibilities.

$25 \mathrm{AC}$ would require substantial data and thus could only be implemented for a few species of highest concern.

26 Many exotic species provide important ecosystem services.

27 The ultimate decision regarding the management of common resources in a democratic system is necessarily a public one

28 Novel, human designed ecosystems are poor ecological cousins of unaltered wildlands.

29 Many areas are so disturbed that they already have ecosystems almost exclusively colonized artificially.

30 The time to implement $A C$ is short and it is not possible to predict all impacts.

31 Viewed under a longer timeline, humans are simply a part of nature.

32 Species movements in and out of particular landscapes are unexceptional and widespread.

$33 \mathrm{AC}$ challenges the distinction between what is a given of the natural world and what is acceptable for human manipulation.

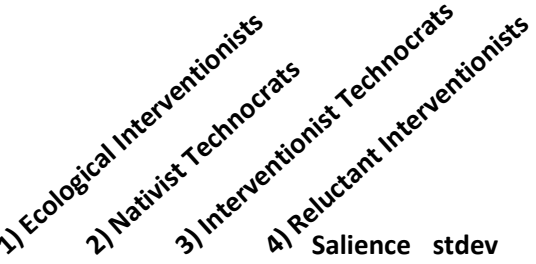

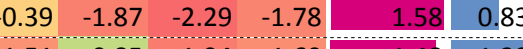

\begin{tabular}{rrrrr|r|r|}
-1.51 & 0.85 & -1.94 & -1.60 & 1.48 & 1.28 \\
\hline 0.88 & 1.37 & 1.78 & 1.47 & 138 & 0.37
\end{tabular}

$\begin{array}{llllll}0.88 & 1.37 & 1.78 & 1.47 & 1.38 & 0.37 \\ 1.59 & 0.80 & 1.01 & 1.94 & 134 & 0.52\end{array}$

\begin{tabular}{l|l|l|l|l|l|l|l|l|l|l|l}
1.59 & 0.80 & 1.01 & 1.94 & 1.34 & 0.52 \\
\hline
\end{tabular}

\begin{tabular}{rrrrr|r|r|r|r|}
-0.87 & -1.48 & 1.52 & -1.16 & 1.26 & 1.37 \\
\hline
\end{tabular}

$\begin{array}{llllll}-1.55 & 1.24 & -0.86 & -1.07 & 1.18 & 1.23 \\ -1.74 & -0.60 & -0.50 & -1.50 & -1.09 & 0.63\end{array}$

\begin{tabular}{rrrr|r|r}
-1.74 & -0.60 & -0.50 & -1.50 & -1.09 & 0.63
\end{tabular}

$\begin{array}{llllll}1.13 & 0.17 & 1.11 & 1.54 & 0.99 & 0.58\end{array}$

$\begin{array}{llllll}1.62 & 1.50 & 0.37 & 0.45 & 0.99 & 0.67\end{array}$

$\begin{array}{lllllll}0.30 & 0.71 & 2.04 & -0.89 & 0.99 & 1.21\end{array}$

$\begin{array}{llllll}1.18 & 0.65 & 1.05 & 0.98 & 0.97 & 0.23\end{array}$

\begin{tabular}{llll|l|l|l|l|l}
-0.53 & 0.91 & 1.18 & -1.13 & 0.94 & 1.12 \\
\hline
\end{tabular}

\begin{tabular}{lllllll|l}
-1.17 & 1.40 & -0.83 & -0.18 & 0.90 & 1.14 \\
\hline
\end{tabular}

\begin{tabular}{lllllll}
1.21 & -1.21 & 0.59 & 0.53 & 0.89 & 1.04 \\
\hline
\end{tabular}

\begin{tabular}{llllllll}
0.30 & 1.29 & 0.37 & 1.54 & 0.88 & 0.63 \\
\hline 0.60 & 0.37 & -1.35 & 1.02 & & 0.84 & 1.04
\end{tabular}

$\begin{array}{lllllll}0.60 & 0.37 & -1.35 & 1.02 & 0.84 & 1.04\end{array}$

\begin{tabular}{lllll|l|l|l|l}
0.23 & -1.14 & -0.36 & -1.55 & & 0.82 & 0.80
\end{tabular}

$\begin{array}{lllllllll}0.77 & -0.91 & -0.89 & -0.61 & & 0.80 & 0.80\end{array}$

$\begin{array}{lllllllll}0.77 & -0.91 & -0.89 & -0.61 & 0.80 & 0.80\end{array}$

\begin{tabular}{llllll|l|l|l}
-1.58 & -1.01 & -0.42 & -0.06 & 0.77 & 0.67
\end{tabular}

\begin{tabular}{lllllll|l}
1.12 & 0.66 & -0.55 & 0.59 & 0.73 & 0.71 \\
\hline
\end{tabular}

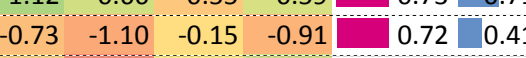

$\begin{array}{lllllllll}-0.37 & -1.76 & 0.07 & 0.64 & 0.71 & 1.02\end{array}$

$\begin{array}{llllllll}0.64 & -1.22 & 0.61 & 0.10 & 0.64 & 0.87\end{array}$

\begin{tabular}{lllllllll}
-1.39 & -0.01 & 0.71 & -0.15 & 0.57 & 0.87 \\
\hline
\end{tabular}

$\begin{array}{lllllllll}0.54 & -0.63 & -0.65 & 0.42 & 0.56 & 0.65\end{array}$

$\begin{array}{lllllllll}-0.67 & -0.19 & -0.23 & 0.72 & 0.45 & 0.58\end{array}$

\begin{tabular}{llllll|l|l|l}
0.12 & 1.18 & -0.15 & -0.31 & 0.44 & 0.67
\end{tabular}

\begin{tabular}{lllllllll}
0.41 & 0.38 & -0.50 & 0.41 & 0.43 & 0.45 \\
\hline
\end{tabular}

$\begin{array}{llllllll}0.89 & -0.09 & -0.45 & -0.13 & 0.39 & 0.58\end{array}$

$\begin{array}{llllllll}0.42 & -0.31 & 0.37 & 0.14 & 0.31 & 0.33\end{array}$

\begin{tabular}{cccc|c|c|}
-0.48 & 0.42 & 0.18 & 0.28 & 0.38 \\
\hline & 0.10 & 0.07 & 0.81 & 0.27 & 0.42
\end{tabular} 
Correlation with other factors

\begin{tabular}{|c|c|c|c|c|c|}
\hline Factor name & Defining characteristics & 1 & 2 & 3 & 4 \\
\hline $\begin{array}{l}\text { 1) Ecological } \\
\text { Interventionists }\end{array}$ & $\begin{array}{l}\text { Open to intensive management, including } \\
\text { AC; benefits outweigh risks; ecosystems } \\
\text { are dynamic but native species matter; } \\
\text { sense of urgency. }\end{array}$ & 1 & 0.136 & 0.353 & 0.613 \\
\hline $\begin{array}{l}\text { 2) Nativist } \\
\text { Technocrats }\end{array}$ & $\begin{array}{l}\text { Eschew human intervention in nature; } \\
\text { extensive uncertainty remains, therefore } \\
\text { refrain from taking action. }\end{array}$ & - & 1 & 0.152 & 0.310 \\
\hline $\begin{array}{l}\text { 3) Interventionist } \\
\text { Technocrats }\end{array}$ & $\begin{array}{l}\text { Open to AC, though perceive significant } \\
\text { risks; AC decision-making should be left to } \\
\text { experts; endangered species laws are a } \\
\text { barrier to AC and thus need to be changed. }\end{array}$ & - & - & 1 & 0.373 \\
\hline $\begin{array}{l}\text { 4) Reluctant } \\
\text { Interventionists }\end{array}$ & $\begin{array}{l}\text { AC may be necessary, but it will not be a } \\
\text { panacea and it comes with major risks; } \\
\text { comparatively amenable to public input. }\end{array}$ & - & - & - & 1 \\
\hline
\end{tabular}


Supplementary Table 1: Published sources of statements forming the concourse.

Becker, W., 2009. Climate and the Age of Faustian Choices. Conservation Biology 23, 794-795.

Camacho, A.E., 2010. Assisted Migration: Redefining Nature and Natural Resource Law Under Climate Change. Yale Journal on Regulation 27, 171-397.

Center for Plant Conservation, 2011. In response to the Feb. 7, 2011 All Things Considered piece entitled - A Growing Risk? Endangered Plants for Sale Online by Nell Greenfieldboyce [WWW Document]. URL http://www.centerforplantconservation.org/News/PressReleases/2011-0209_Response_to_A_Growing_Risk.pdf

Colombo, S., 2008. Ontario's forests and forestry in a changing climate. Applied Research and Development Branch Ontario Ministry of Natural Resources, Peterborough.

Colombo, S.J., Boysen, B., Brosemer, K., Foley, A., Obenchain, A., 2010. Managing tree seed in an uncertain climate: conference summary [WWW Document]. URL https://ozone.scholarsportal.info/handle/1873/13859

Davidson, I., Simkanin, C., 2008. Skeptical of assisted colonization. Science 322, $1048 \mathrm{~b}$.

Ecological Society of Australia, 2010. Position Statement: Climate Change [WWW Document]. A Position Statement by the Ecological Society of Australia. URL http://www.ecolsoc.org.au/Position_papers/ClimateChange.htm

Fazey, I., Fischer, J., 2009. Assisted colonization is a techno-fix. Trends in Ecology \& Evolution 24, 475.

Fox, D., 2007. When Worlds Collide. Conservation in Practice 8, 28-34.

Galatowitsch, S., Frelich, L., Phillips-Mao, L., 2009. Regional climate change adaptation strategies for biodiversity conservation in a midcontinental region of North America. Biological Conservation 142, 2012-2022.

Gardiner, S.M., 2004. Ethics and Global Climate Change. Ethics 114, 555-600.

Hannah, L., Midgley, G.F., Lovejoy, T., Bond, W.J., Bush, M., Lovett, J.C., Scott, D., Woodward, F.I., 2002. Conservation of Biodiversity in a Changing Climate. Conservation Biology 16, 264-268.

Hewitt, N., Klenk, N., Smith, A.L., Bazely, D.R., Yan, N., Wood, S., MacLellan, J.I., LipsigMumme, C., Henriques, I., 2011. Taking stock of the assisted migration debate. Biological Conservation 144, 2560-2572.

Hoegh-Guldberg, O., Hughes, L., McIntyre, S., Lindenmayer, D.B., Parmesan, C., Possingham, H.P., Thomas, C.D., 2008. Ecology. Assisted colonization and rapid climate change. Science (New York, NY) 321, 345.

Hunter, M.L., 2007. Climate change and moving species: furthering the debate on assisted colonization. Conservation Biology 21, 1356-1358.

Hunter, M.L., Jacobson, G.L., Webb, T., 1988. Paleoecology and the Coarse-Filter Approach to Maintaining Biological Diversity. Conservation Biology 2, 375385. 
Johnston, M., 2009. Vulnerability of Canada's tree species to climate change and management options for adaptation an overview for policy makers and practitioners. Canadian Council of Forest Ministers,, Ottawa, Ont. :

Kreyling, J., Bittner, T., Jaeschke, A., Jentsch, A., Jonas Steinbauer, M., Thiel, D., Beierkuhnlein, C., 2011. Assisted Colonization: A Question of Focal Units and Recipient Localities. Restoration Ecology no-no.

Marinelli, J., 2010. Guardian Angels. Audubon.

McLachlan, J.S., Hellmann, J.J., Schwartz, M.W., 2007. A framework for debate of assisted migration in an era of climate change. Conserv. Biol 21, 297-302.

Millar, C.I., Stephenson, N.L., Stephens, S.L., 2007. CLIMATE CHANGE AND FORESTS OF THE FUTURE: MANAGING IN THE FACE OF UNCERTAINTY. Ecological Applications 17, 2145-2151.

Minteer, B.A., Collins, J.P., 2010. Move it or lose it? The ecological ethics of relocating species under climate change. Ecological Applications 20, 1801-1804.

NPR, 2011. A Growing Risk? Endangered Plants For Sale Online : NPR [WWW Document]. URL http://www.npr.org/templates/transcript/transcript.php?storyId=1335654 94

Price, M.R.S., 2010. Assisted Colonization: Move Ahead with Models. Science 330, 1317.

Ricciardi, A., Simberloff, D., 2009a. Assisted colonization is not a viable conservation strategy. Trends in Ecology \& Evolution 24, 248-253.

Ricciardi, A., Simberloff, D., 2009b. Assisted colonization: good intentions and dubious risk assessment. Trends in Ecology and Evolution 24, 476-477.

Richardson, D.M., Hellmann, J.J., McLachlan, J.S., Sax, D.F., Schwartz, M.W., Gonzalez, P., Brennan, E.J., Camacho, A., Root, T.L., Sala, O.E., Schneider, S.H., Ashe, D.M., Clark, J.R., Early, R., Etterson, J.R., Fielder, E.D., Gill, J.L., Minteer, B.A., Polasky, S., Safford, H.D., Thompson, A.R., Vellend, M., 2009. Multidimensional evaluation of managed relocation. Proceedings of the National Academy of Sciences 106, $9721-9724$.

Sandler, R., 2010. The Value of Species and the Ethical Foundations of Assisted Colonization. Conservation Biology 24, 424-431.

Sauchyn, D., 2009. Saskatchewan's Natural Capital in a Changing Climate: An Assessment Of Impacts And Adaptation. Report to Saskatchewan Ministry of Environment from the Prairie Adaptation Research Collaborative.

Sax, D.F., Smith, K.F., Thompson, A.R., 2009. Managed relocation: a nuanced evaluation is needed. Trends in Ecology \& Evolution 24, 472-473.

Schlaepfer, M.A., Helenbrook, W.D., Searing, K.B., Shoemaker, K.T., 2009. Assisted colonization: evaluating contrasting management actions (and values) in the face of uncertainty. Trends in Ecology \& Evolution 24, 471-472.

Schwartz, M.W., Hellmann, J.J., McLachlan, J.S., 2009. The precautionary principle in managed relocation is misguided advice. Trends in Ecology \& Evolution 24, 474.

Seddon, P.J., 2010. From Reintroduction to Assisted Colonization: Moving along the Conservation Translocation Spectrum. Restoration Ecology 796-802. 
Seddon, P.J., Armstrong, D.P., Soorae, P., Launay, F., Walker, S., Ruiz-Miranda, C.R., Molur, S., Koldewey, H., Kleiman, D.G., 2009. The risks of assisted colonization. Conservation Biology 23, 788-789.

Shirey, P.D., Lamberti, G.A., 2010. Assisted colonization under the US Endangered Species Act. Conservation Letters 3, 45-52.

Shirey, P.D., Lamberti, G.A., 2011. Regulate trade in rare plants. Nature 469, 465467.

Southgate, C., Hunt, C., Horrell, D., 2008. Ascesis and assisted migration: responses to the effects of climate change on animal species. European Journal of Science and Theology 4, 99-111.

St.Clair, B., Howe, G.T., 2009. Genetic Options for Adapting Forests to Climate Change. Western Forester.

St.Clair, J., Howe, G.T., 2007. Genetic maladaptation of coastal Douglas-fir seedlings to future climates. Global Change Biology 13, 1441-1454.

Stone, R., 2010. Home, Home Outside the Range? Science 329, $1592-1594$.

Van der Veken, S., Hermy, M., Vellend, M., Knapen, A., Verheyen, K., 2008. Garden plants get a head start on climate change. Frontiers in Ecology and the Environment 6, 212-216.

Vitt, P., Havens, K., Kramer, A.T., Sollenberger, D., Yates, E., 2010. Assisted migration of plants: Changes in latitudes, changes in attitudes. Biological Conservation $143,18-27$. 
Supplementary Table 2: Participant characteristics and factor loadings.

\section{Conservation Scientists}

Ecosystem ecologist (plants), boreal forests ${ }^{\text {m, Ph.D., USA }}$

Ecologist (plants), W. USA ${ }^{\text {m, Ph.D., USA }}$

Plant physiologist (native terrestrial plants), E. USA ${ }^{\text {m, Ph.D., USA }}$

Conservation biologist (birds, butterflies, humans), W. USA f, Ph.D., USA

Ecologist (Plants, fungi, insects, mammals), E. North America m, Ph.D., USA

Ecosystem ecologist (plants), boreal forests ${ }^{m, ~ P h . D ., ~ U S A ~}$

Conservation biologist (plants), South Africa m, Ph.D., s. Africa

Evolutionary ecologist (plants), North America f, Ph.D., USA

Spatial ecologist (plants), W. USA f, Ph.D., USA

Ecologist (plants), W. USA f, Ph.D., USA

Ecologist (insects, algae, fish), W. USA f, Ph.D., USA

Disease ecologist (mammals, birds, arthropods), NE USA m, Ph.D., USA

Ecologist (forests, grasslands), North America ${ }^{m, \text { Ph.D., USA }}$

Restoration ecologist (plants), tropics and W. USA f, Ph.D., USA

Ecologist (plants), Mediterranean f, Ph.D., Spain

Global change ecologist (plants), SW USA ${ }^{\text {m, Ph.D., USA }}$

Ecologist (plants), high elevation ecosystems worldwide m, Ph.D., USA

Ecosystem ecologist (trees, microbes, insects), W. \& S. USA f, Ph.D., USA

Ecologist (plants, animals), Australia f, Ph.D., Australia

Community ecologist (plants), NW USA f, Ph.D., USA

Global ecologist (plants), Australia ${ }^{m, \text { Ph.D., Australia }}$

Marine ecologist (marine invertebrates), coastal USA m, Ph.D., USA

Community ecologist (insects), North America m, Ph.D., USA

Ecologist-biosphere dynamics (plants), global ${ }^{m}$, Ph.D., Germany

\section{Ontario Forest Managers}

Forestry ministry scientist ${ }^{\text {f, Ph.D. }}$

Forestry policy maker ${ }^{m}$, Ph.D.

Conservation forester ${ }^{\mathrm{f}, \mathrm{BS}}$

Government forester $m$, Ms

Conservation forester ${ }^{m, B S}$

Government forester m, Ph.D.

Forestry policy maker ${ }^{m, B S}$

Forestry policy maker $\mathrm{f}$, Ms

Forestry ministry scientist ${ }^{m, \text { Ph.D. }}$

Forestry policy maker ${ }^{m, B S}$

Forestry ministry scientist ${ }^{m, M S}$

Forestry ministry scientist ${ }^{f, P h . D .}$

Forestry ministry scientist ${ }^{m, ~ P h . D . ~}$

Government forester $^{m, M s}$

\begin{tabular}{|c|c|c|c|}
\hline & 2 & 3 & \\
\hline-0.03 & 0.53 & 0.42 & 0.03 \\
\hline .09 & 0.75 & .11 & $0.1 \varepsilon$ \\
\hline 0.33 & 0.31 & 0.15 & 0.56 \\
\hline 0.20 & 0.24 & -0.01 & 0.57 \\
\hline 0.23 & 0.79 & -0.09 & 0.13 \\
\hline 0.40 & 0.42 & 0.48 & 0.26 \\
\hline 0.51 & 0.28 & 0.05 & 0.16 \\
\hline 0.54 & -0.01 & -0.04 & 0.42 \\
\hline 0.36 & 1 & 0.10 & 0.50 \\
\hline 0.64 & 0.01 & -0.26 & 0.19 \\
\hline 0.02 & 0.76 & 0.29 & 0.06 \\
\hline 0.74 & 0.05 & 0.09 & 0.35 \\
\hline 0.68 & -0.10 & 0.18 & 0.30 \\
\hline 0.40 & 0.24 & 0.02 & 0.50 \\
\hline 0.08 & 0.66 & -0.13 & -0.10 \\
\hline 0.4 & -0. & 8 & $6 \varepsilon$ \\
\hline 0.23 & 0.61 & -0.33 & 0.27 \\
\hline 0.22 & 0.69 & 0.34 & 0.12 \\
\hline 0.73 & -0.12 & 0.02 & 0.43 \\
\hline 0.31 & . & 0.52 & 01 \\
\hline 0.50 & -0.22 & -0.14 & 010 \\
\hline-0.08 & & 0.00 & 0.42 \\
\hline 0.70 & 2 & 0.25 & 0 \\
\hline 0.08 & 0.29 & 0.21 & 0.52 \\
\hline 0.23 & 0.00 & 0.67 & 0.10 \\
\hline 0.27 & 016 & 0.08 & $06 ?$ \\
\hline 0.57 & -0.09 & 0.45 & 0.15 \\
\hline-0. & & $0-$ & 0 \\
\hline 0.20 & 0. & 0.57 & 0.09 \\
\hline 0.19 & -0.08 & 0.35 & 0.58 \\
\hline 0.61 & 0. & 3 & 0.1 \\
\hline 0.52 & -0.3 & 0.09 & 0.49 \\
\hline 0.69 & -0.46 & -0.04 & 0.2 \\
\hline 0.52 & -0.24 & 0.14 & .0 \\
\hline 0.40 & 0.05 & 0.48 & 0.33 \\
\hline 0.02 & 0.45 & 0.06 & \\
\hline 0.36 & 0.16 & 0.33 & 0.29 \\
\hline-0.0 & -0.04 & 0.68 & ? \\
\hline
\end{tabular}




$$
\begin{aligned}
& \text { Forestry ministry scientist }{ }^{\mathrm{m}, \mathrm{MS}} \\
& \text { Forestry ministry scientist }^{\mathrm{m}, \mathrm{MS}} \\
& \text { Protected spaces }^{\mathrm{m}, \text { Ph.D. }} \\
& \text { Forestry policy maker }^{\mathrm{m}, \mathrm{BS}} \\
& \text { Forestry ministry scientist }^{\mathrm{m}, \text { Ph.D. }} \\
& \text { Government forester }^{\mathrm{m}, \mathrm{MS}} \\
& \text { Industrial forester }^{\mathrm{m}, \mathrm{BS}} \\
& \text { Government forester }^{\mathrm{m}, \mathrm{BS}} \\
& \text { Forestry policy maker }^{\mathrm{m}, \mathrm{BS}} \\
& \text { Conservation forester }^{\mathrm{m}, \mathrm{Ph} . D .} \\
& \text { Conservation forester }^{\mathrm{m}, \mathrm{MS}} \\
& \text { Conservation forester }^{\mathrm{m}, \mathrm{BS}}
\end{aligned}
$$

\begin{tabular}{rrrrr} 
& 0.68 & 0.10 & 0.05 & 0.15 \\
\hline 0.49 & 0.27 & -0.30 & 0.43 \\
-0.04 & 0.85 & 0.16 & -0.10 \\
-0.07 & 0.54 & 0.14 & 0.00 \\
& 0.60 & -0.21 & 0.38 & 0.34 \\
& 0.54 & 0.25 & 0.00 & 0.09 \\
& 0.53 & -0.18 & 0.24 & 0.59 \\
& 0.63 & 0.31 & 0.34 & 0.29 \\
& 0.30 & 0.14 & 0.06 & 0.78 \\
& 0.61 & 0.26 & 0.54 & -0.21 \\
& 0.63 & 0.15 & 0.15 & 0.10 \\
\hline \% Variability explained & 19 & 13 & 9 & 13 \\
& -0.07 & 0.11 & 0.52 & -0.05 \\
\hline Number of defining variables & 16 & 11 & 4 & 10
\end{tabular}

